\title{
MICROMACHINING AND MICROGENETICS: WHAT ARE THEY AND WHERE DO THEY WORK TOGETHER?
}

\author{
Michael Albin, Reid Kowallis, Enrico Picozza, Yefim Raysberg, \\ Chuck Sloan, Emily Winn-Deen, Tim Woudenberg and Jerry Zupfer \\ Applied Biosystems Division of Perkin Elmer Corp., \\ 850 Lincoln Centre Drive, Foster City, CA 94404.
}

\begin{abstract}
PCR provides specific amplification of very small quantities of DNA by employing DNA polymerase extension under tightly-controlled temperature cycling. The reactions are typically performed in 10's to 100's of microliters in plastic tubes. The role of silicon-based processing in improving upon the PCR process (cost and performance) by reducing sample requirements, increasing throughput, and improving temperature cycling uniformity and ramping rates are contrasted with issues regarding surface chemistry and user interfaces at small scales. A platform for preparing testarrays and cycling of multiple sites with direct monitoring of temperature AND reaction progress is demonstrated in both silicon and molded, plastic parts. The relevance to genetic screening is addressed.
\end{abstract}

\section{INTRODUCTION}

The polymerase chain reaction (PCR) [1] has demonstrated widespread utility in the area of genetic analysis. This simple process, which mimics the cell's natural ability to reproduce DNA, has been used as a core technology by many researchers to specifically amplify small target regions of DNA and to produce sufficient material for further analysis. Two primers, one for each DNA strand, are used to direct selective chain replication by DNA polymerase. As each chain is replicated it creates a copy of the original template. Thermal denaturation of these copies from the original template results in four strands which can be replicated in the next cycle. By employing successive cycles of high temperature thermal denaturation and lower temperature primer annealing and chain extension, exponential amplification of the target sequence bracketed by the two primers is achieved. The use of thermal stable DNA polymerases has facilitated PCR automation in a programmable heating block or thermal cycler.

The early years of PCR (1985-1993) have focused on low throughput usage in a vast array of research projects. The current trend is toward an increasing number of applied markets using PCR for routine analysis of specific DNA targets. As research work evolves into screening programs, sample throughput must increase dramatically. Rapid statistical data analysis and a reduction in cost per test are also needed. This need must be met by simple, low-cost instrumentation and systems integration from specimen preparation through amplification, product detection and data interpretation. The primary segments of the market where such simple, high throughput PCR systems are expected to dominate are drug efficacy monitoring, infectious disease testing in humans, animals, plants, food and the environment, human genetic disease testing, biodiversity monitoring, and DNA identification. With conventional systems the cost per test, calculated on a relatively high volume reaction $(25-50 \mu \mathrm{L})$, gives a fairly high, average value of $\$ 1$ per reaction.

Recent improvements in PCR amplification include development of special thin walled amplification tubes and glass capillaries which facilitate thermal exchange between the cycling block and the reagents, greatly reducing total PCR cycle time, introduction of a heated lid which eliminates the need to cover the reaction with oil in order to prevent evaporation during thermal cycling, development of homogeneous hot start techniques, and the ability to run PCR in situ on tissue sections mounted on microscope slides.

After completion of the PCR reaction the products must still be detected. In most early work, products from amplification reactions were evaluated by simple gel electrophoresis using gels stained with an intercalating dye such as ethidium bromide. Later they were quantitated by gel electrophoresis on a fluorescent DNA sequencer. Other methodologies have been developed to enable colorometric, multiplex detection capability. Higher density multiplex detection will be possible with some of the hybridization array chips under development now by companies such as Affymetrix [2] and Nanogen [3]. These arrays contain many capture probes and are designed to provide a yes/no answer as to whether a particular sequence is present in the target DNA. Both depend on performing PCR as an upstream step prior to detection of the PCR product by hybridization.

Many future PCR applications will require both real time detection and self-contained devices. Tubes may disappear and be replaced with miniature well arrays on a silicon chip (a sort of mini-microtiter plate). Several groups have demonstrated the feasibility of performing PCR in a chamber made of silicon [4,5]. Small volume PCR (5-10 uL) has been carried out in these chips using a computer controlled Peltier heater/cooler. The next step in miniaturization for PCR will include integration of PCR and amplification product detection. Here we report the first integrated PCR thermal cycling and detection system in chip format.

\section{EXPERIMENTAL DETAILS}

The system concept for high-throughput, genetic screening based-upon real-time, quantitative detection for PCR is depicted in Figure 1. A translation stage holds a slide 
that contains individually addressable, cycling regions (for each chip) that are imaged at the end of each cycle. The detector consists of a tungsten bulb illumination source, a CCD camera and appropriate focusing/collection optics. The following sections detail aspects of the system and its performance.

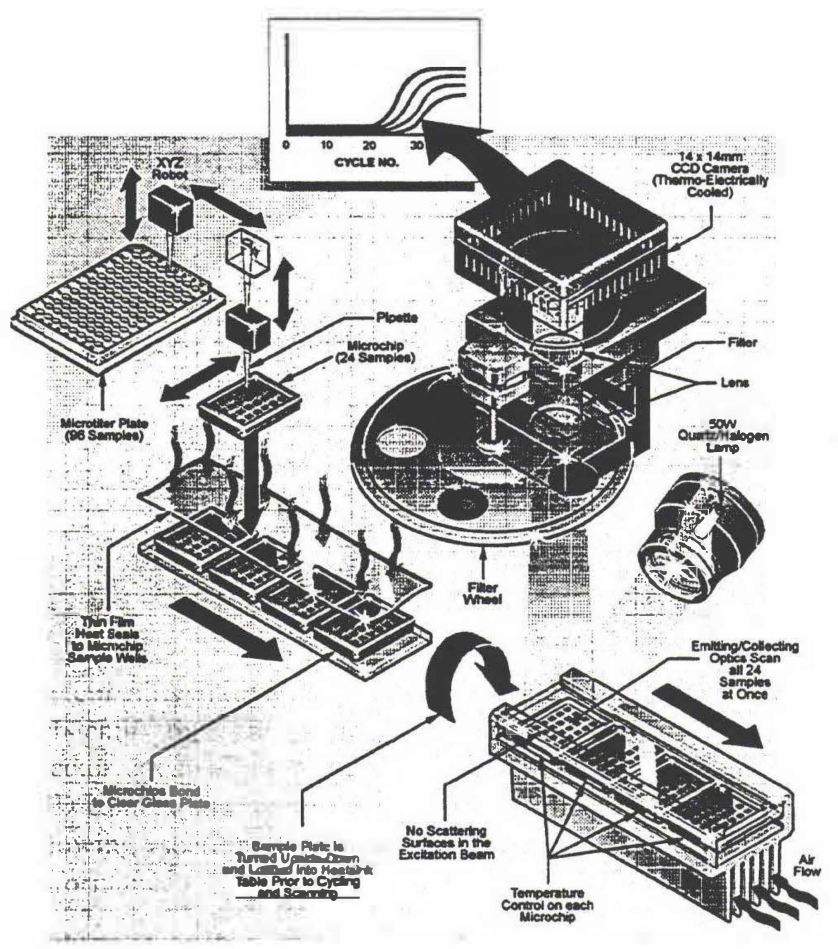

Figure 1. Schematic of PCR system: chips anodically bonded to a glass surface are loaded robotically; sealed with a polymer membrane; flipped for optical detection through the glass; thermal-cycled with on-chip resistive heaters or extemal peltiers; and imaged as cycling proceeds.

\section{Chip Design:}

Figure 2 shows designs of silicon test chips for PCR. The top row shows top/bottom views of a $14 \mathrm{~mm} x$ $14 \mathrm{~mm}$ structure consisting of eight $5 \mu \mathrm{L}$ wells with a $4000 \AA$ thermal oxide coating. The larger entry holes $(0.5 \mathrm{~mm} \times 0.5$ $\mathrm{mm}$ ) allow for manual loading of individual wells. They are offset to minimize contamination as reagents are loaded manually. The bottom row illustrates the well layout and two designs in which resistive traces (aluminum) are deposited to provide a direct means to 'power' the devices.

Proportional, Integral, Differential (PID) control over sample temperature is established by one of two alternative means (on-chip and off-chip methods). The offchip method uses a Marlow Industries model SE5020 temperature controller to drive a ITI Ferro Tec model 6300 peltier device. A maximum drive current of \pm 5 amps enables the device to be ramped at $\pm 4^{\circ} \mathrm{C} / \mathrm{s}$ (average rate over a $55^{\circ} \mathrm{C}$ $95^{\circ} \mathrm{C}$ ramp). This design relies on a platen of uniform temperature which is very close to the sample temperature when at steady state. A $0.5^{\circ} \mathrm{C}$ uniformity for the chip can be realized in this format. The drawbacks are that the ramping is slower than can be realized with on-chip heaters, and that there is an issue of longevity of the thermal electric scheme which is currently employed.
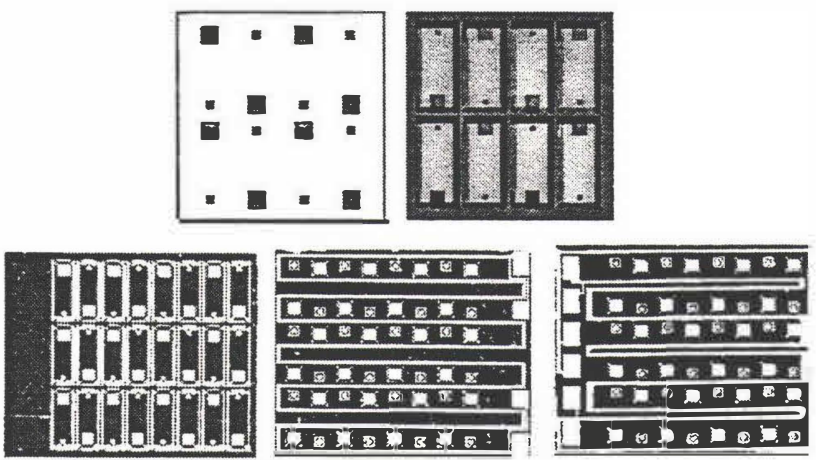

Figure 2: Layouts of chips for PCR testing - Top: 8 - 5 $4 L$ wells, Bottom: $24-2 \mu L$ wells.

The on-chip method uses one or two zones of resistance heating which can establish a maximum power dissipation of 25 Watts over the $200 \mathrm{~mm}^{2}$ area chip. This results in a measured average temperature ramp rate of $10^{\circ} \mathrm{C} / \mathrm{sec}$ over the transistion from $55^{\circ} \mathrm{C}$ to $95^{\circ} \mathrm{C}$. Most of the time during this transition is spent closing out the ramp in a manner which does not allow more than $0.5^{\circ} \mathrm{C}$ of overshoot. These designs work by continuously applying a thermal loss to the silicon chip, such that the $10^{\circ} \mathrm{C} / \mathrm{sec}$ down rate is accomplished merely by turning off the heater power. Hence at $95^{\circ} \mathrm{C}$ the heat flux through the chip is large. Unless the sourcing and sinking of heat is quite uniform, there will be significant non-uniformity in the steady state temperature profile. The temperature uniformity at different stages were assessed with InfraRed thermography (Fig. 3). The images depict system performance in actual use configuration at $95^{\circ} \mathrm{C}$. The results indicate a steady-state difference in temperature of $5.2^{\circ} \mathrm{C}$ from the hottest to coldest point in the left design (single element) and $2.0^{\circ} \mathrm{C}$ in the subsequent modification. This is still not sufficiently uniform for precision PCR work.

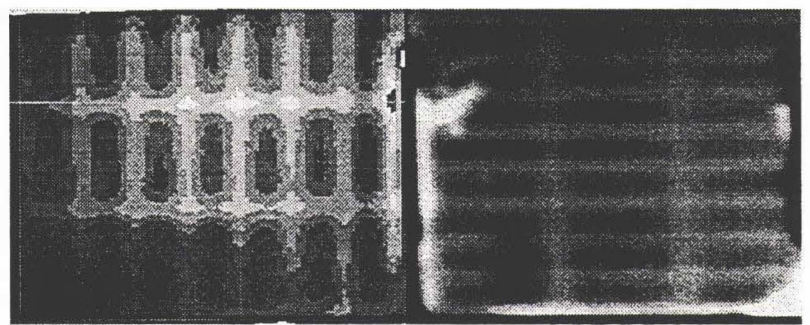

Figure 3. Thermal images of two different on-chip heater designs as shown in Figure 2 (InfraMetrics Model 740 Infra Red camera configured with a $77 \mathrm{~K} \mathrm{HgCdTe}$ detector). 
Chip loading:

The intent for an initial system would be to put the burden on the manufacturer in terms of pre-loading the microstructures so that the user would merely need to introduce the sample(s). A dispensing robot (Asymtek, Automove 402) coupled to drop-on-demand, ink-jet printing heads provide a tool for precisely delivering fluids to the inlets of the small structures (Figure 4). The system specifications are as follows:

Robot: X, Y-axis - work table, 12"x12"; resolution: 001"; velocity: 0-20 inches/sec.; repeatability, +/- 0.001". Z-axis - travel, 3.5"; resolution, 0.001"; velocity, 0-8 inches/second.

Options: tip locator, offset camera, strobe drop camera, on-axis camera, gravimetric drop calibration.

Printing Head: Type - drop-on-demand, PiezoElectric; Wetted Surfaces - Glass, Teflon, Polypropylene; Minimum Drop Volume - $125 \mathrm{pL}$; Maximum Flow: $1 \mu \mathrm{l} / \mathrm{min}$; Max Duty Cycle: $66 \%$.
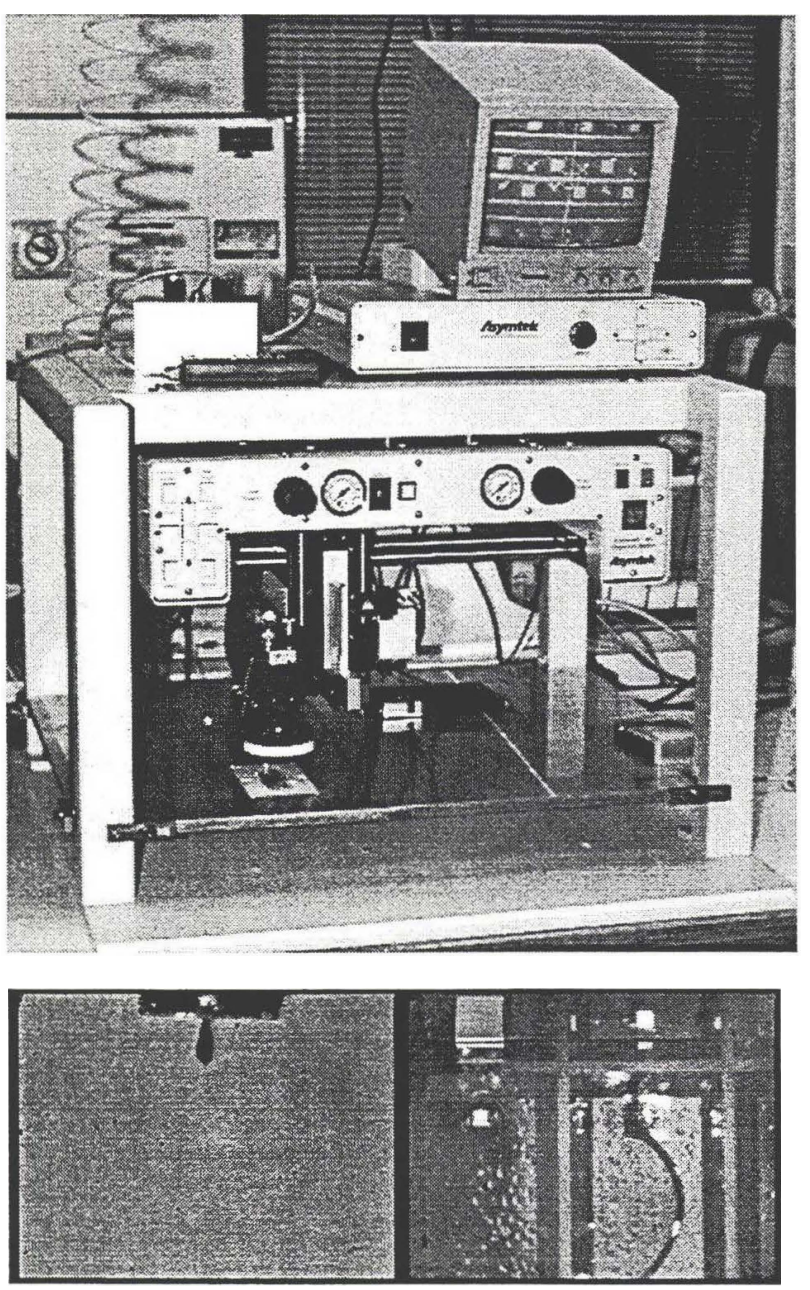

Figure 4. Chip loading configuration: Top - Robotic work station - screen image displays portion of slide with $0.5 \mathrm{~mm} x$ $0.5 \mathrm{~mm}$ entry ports for fluid loading; wells $=2 \mu \mathrm{L}$, slides are located beneath CCD camera at the system base. Bottom droplet formation at tip; fluid at entry port entering well.
Sample loading:

One concept for a user interface to reagent-loaded arrays is to interconnect a number of wells that would serve to address one sample for multiple test screening. Such a structure is shown in Figure 5. In this configuration, $49-1 \mu \mathrm{L}$ wells are connected by a serpentine channel. The device is evacuable, thereby allowing the user to input a sample which can then be transferred to all connecting wells.
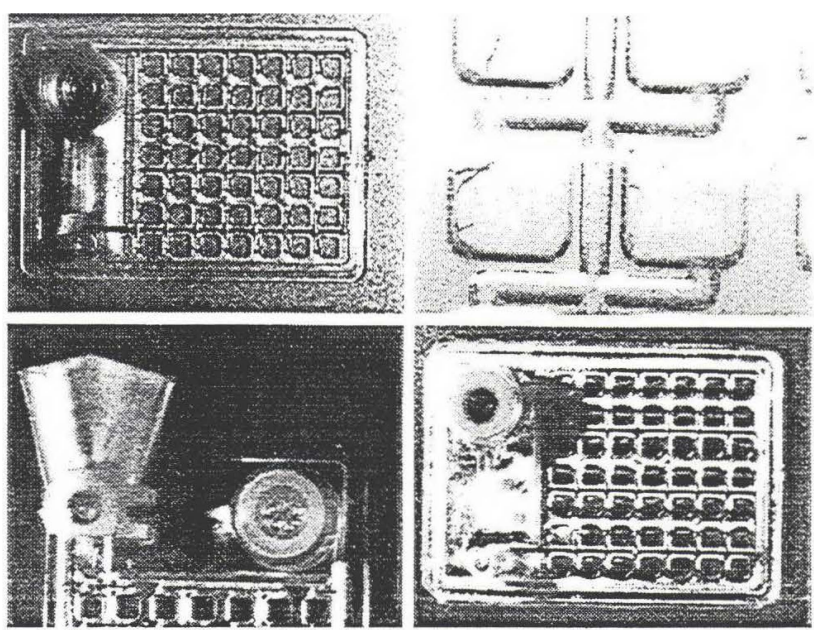

Figure 5. Multi-well plate and injection manifold: Top Device and enlargement of interconnecting channel; Bottom vacuum, injection ports. Wells are $1.2 \times 1.2 \times 0.75 \mathrm{~mm}$ deep $(1.1 \mu \mathrm{L})$; channels are $250 \mu \mathrm{m}$ wide $\times 250 \mu \mathrm{m}$ deep.

In this format, the process steps consist of:

- Filling the devices with reagents by the manufacturer

- applying a vacuum to the device

- Drawing sample into the evacuated device

- Sealing the access ports prior to thermocycling

\section{Amplification and Detection:}

Some of the key issues in performing DNA amplification in small, silicon devices include materials compatibility (does the chemistry work the same in silicon as in polypropylene?), geometry (how does the larger surface/volume area effect performance?), and thermal characteristics (does the higher thermal conductivity permit faster, more robust chemistry?). Materials properties of substrates evaluated for PCR are given in Table I.

In general, PCR in silicon devices has worked best using $4000-5000 \AA$ of thermal oxide grown on the silicon surface; however, this does not provide a general equivalence to polypropylene tube performance. Studies of the interaction of various species present in the PCR reaction mix indicate that enzyme binding to the surface is a critical aspect of the differing performance. Fig. 6 illustrates the results of analysis (ESCA, FISONS 22i XL) of Taq polymerase 
binding to the surface of silicon with a thermal oxide coating versus untreated polypropylene.

Table I. Materials Properties Relevant to PCR

\begin{tabular}{|c|c|c|c|c|}
\hline MATERIAL & $\begin{array}{r}\text { TH. COND. } \\
\left(\mathbf{W} / \mathbf{m}^{\circ} \mathbf{K}\right)\end{array}$ & $\begin{array}{l}\text { MAX USE } \\
\left({ }^{\circ} \mathrm{C}\right)\end{array}$ & $\begin{array}{l}\text { ELEC. RES. } \\
(\mathrm{ohm} / \mathrm{cm})\end{array}$ & $\begin{array}{c}\text { PCR OK } \\
\text { (bare/treated) }\end{array}$ \\
\hline AIR & 0.01 & & & \\
\hline $\begin{array}{l}\text { GLASS } \\
\text { POLY CARB }\end{array}$ & $\begin{array}{l}0.76 \\
0.20\end{array}$ & $\begin{array}{l}260 \\
126\end{array}$ & $\begin{array}{l}5 \text { E } 07 \\
8 \text { E } 16\end{array}$ & $\begin{array}{l}\text { NOYYES } \\
\text { YESYES }\end{array}$ \\
\hline $\begin{array}{l}\text { POLY PROP } \\
\text { SIIICON }\end{array}$ & $\begin{array}{r}0.33 \\
150.00\end{array}$ & $\begin{array}{r}110 \\
1410\end{array}$ & $>\begin{array}{l}>1 \\
4 \mathrm{E} 17 \\
06\end{array}$ & $\begin{array}{l}\text { YESYES } \\
\text { POORYYS }\end{array}$ \\
\hline $\begin{array}{l}\text { ALUMINUM } \\
\text { COPPER }\end{array}$ & $\begin{array}{l}204.00 \\
391.00\end{array}$ & $\begin{array}{r}650 \\
1080\end{array}$ & $\begin{array}{l}4 E-6 \\
2 E-6\end{array}$ & $\begin{array}{l}\text { NOYYS } \\
\text { NOr??? }\end{array}$ \\
\hline PCR BUFFER & 0.65 & & & \\
\hline
\end{tabular}

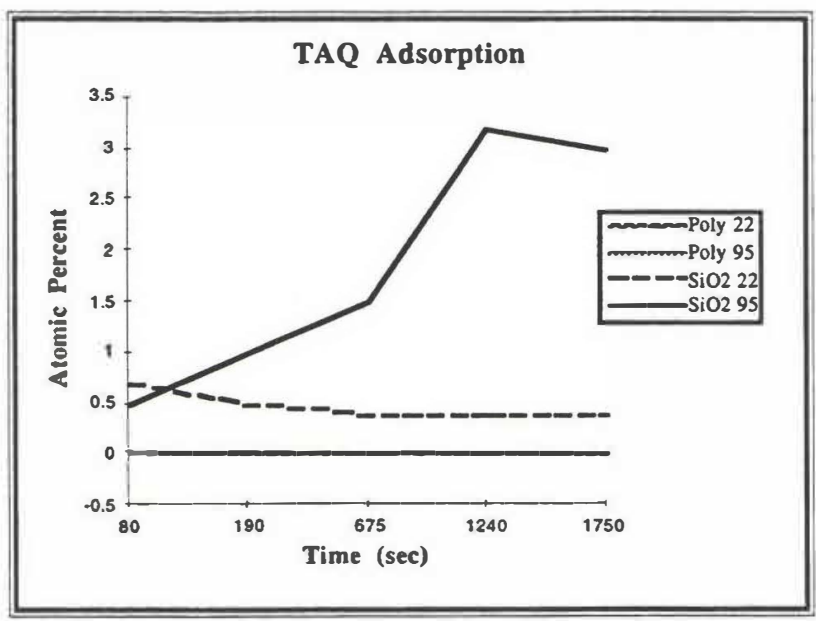

Figure 6. Analysis of enzyme interaction with polypropylene and silicon dioxide surfaces. Inset indicates material and temperature. Atomic \% represents the number of atoms of an element in a volume of 100 atoms near the surface.

Figure 7 illustrates a method that gives a signal to allow realtime homogenous detection of specific PCR products $[6,7]$. This technique makes use of the $5^{\prime}-3^{\prime}$ endonuclease activity of AmpliTaq ${ }^{\circledR}$ DNA polymerase to release fluorescence from a reporter probe during PCR. The reporter probe is doubly labeled with a fluorescent reporter dye and a fluorescence quencher dye. If the target of interest is present, the probe specifically anneals to the target DNA between the forward and reverse primer sites. During primer extension the DNA polymerase allows the enzyme to both extend the primer and cleave the probe thereby releasing the reporter dye from the quencher. This fluorogenic process can be followed in real time, allowing specific detection and quantitation of up to 3 sequences simultaneously over a dynamic range of 5 orders of magnitude in starting target copy number.

The results of an automated run on a system as depicted in Figure 1 are shown in Figure 8 . Positive samples and negative controls were run on distinct devices as cross-talk between silicon wells is a critical issue during manual sample loading in this configuration. The top figure shows real-time images of $8-5 \mu \mathrm{L}$ wells at different time cycles. The $582 \mathrm{~nm}$
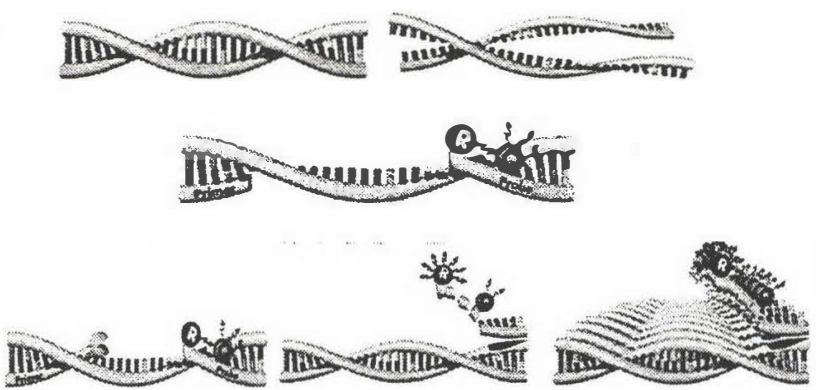

Figure 7. Illustration of $P C R$ reaction and TaqMan ${ }^{\mathrm{TM}}$ format to generate real-time fluorescence signal: Top - denature DNA $\left(95^{\circ} \mathrm{C}\right)$, Center: Anneal Primer and Probe $\left(72^{\circ} \mathrm{C}\right)$; Bottom polymerize $-\cdot>$ fluorescence increases, repeat $x$-times.

images represent reference wavelength data; $518 \mathrm{~nm}$ represents the fluorescent product. The middle panel is the analyzed data showing the exponential growth of amplified product. It is significant to note the offsets between the sets of traces: for a ten-fold change in starting copy number of DNA, an offset of 3-4 cycle numbers for a given intensity is observed as predicted. The last panel shows an off-line analysis of final products by capillary electrophoresis. The product (294 base pairs) appears at $\sim 6 \mathrm{~min}$. and shows minimal side products. Tube controls gave $\sim 2$-fold higher signals.

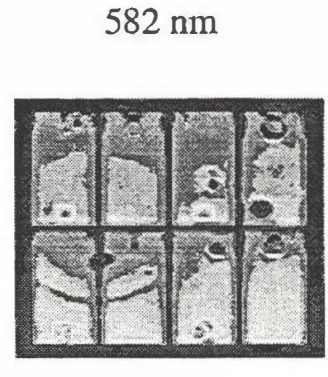

$518 \mathrm{~nm}$
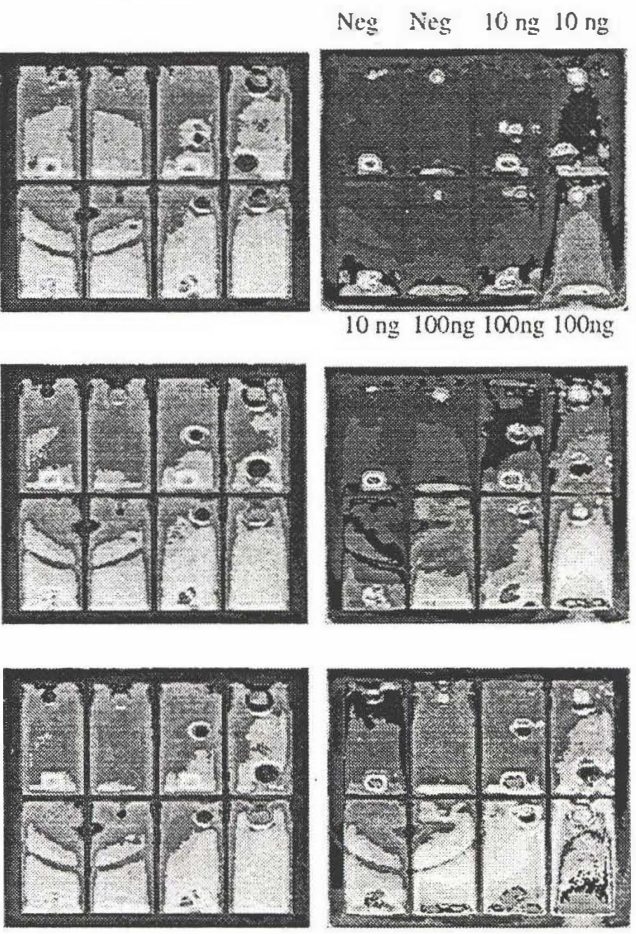

Figure 8 a . Amplification of $\beta$-actin: 40 cycles $\left(96^{\circ} \mathrm{C}, 30 \mathrm{sec}\right.$; $54^{\circ} \mathrm{C}, 30 \mathrm{sec} ; 72^{\circ} \mathrm{C}, 2 \mathrm{~min}$.) with peltier control. Real-time fluorescence images of $P C R$ well arrays; Top = cycle 1 , Middle $=$ cycle 22, bottom $=$ cycle 40 . 


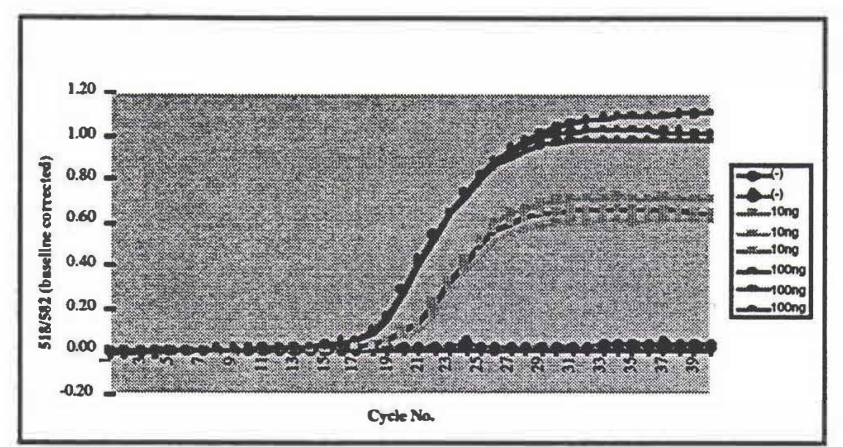

Figure 8 b. Data analysis of Figure 8a.

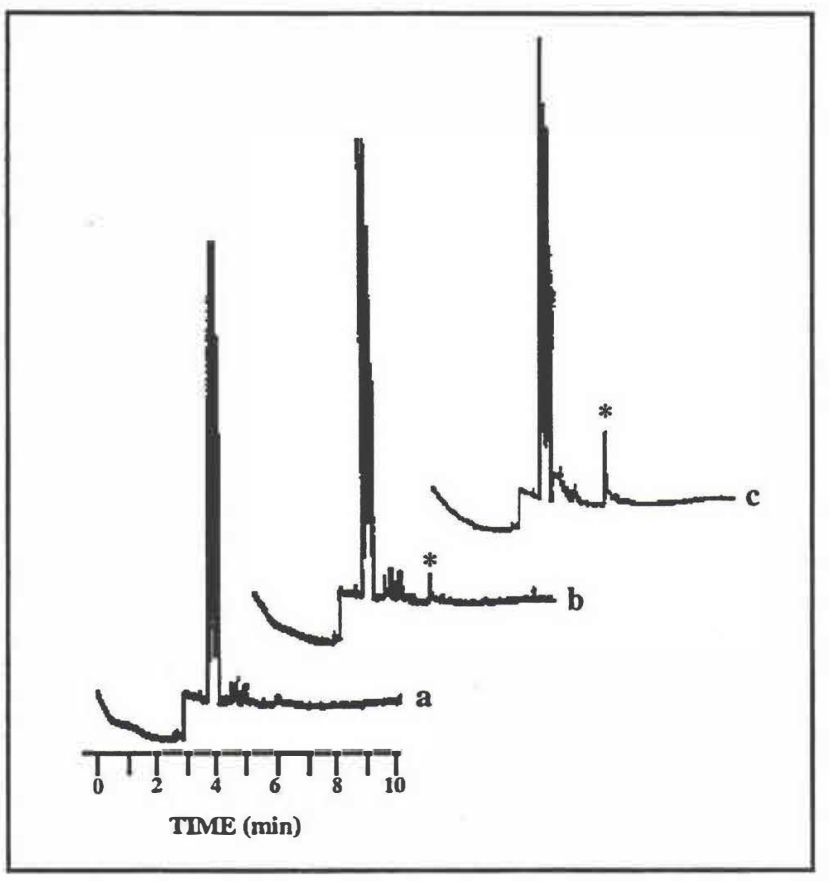

Figure 8. Off-line capillary electrophoresis analysis of PCR reaction products of Figure $8 a$.

\section{CONCLUSIONS}

A number of factors influence the formats in which genetic analysis is performed and the directions of current research. Speed and cost of analyses, simplicity (i.e. integration of analysis components), robustness and throughput are all key issues. In this work we have demonstrated that PCR can work efficiently in silicon-based devices; however, to be cost effective additional efforts in materials/process development must occur. Additional efforts will also focus on incorporation of sample preparation aspects and alternative loading and detection formats (such as capillary electrophoresis shown above) [8-10]. Much of this progress will rely on the development of fluid transfer and device interconnect methodologies.

\section{REFERENCES}

1. R.K. Saiki, S. Scharf, F. Faloona, K.B. Mullis, G.T. Hom, H.A. Erlich, and N. Amheim, "Enzymatic amplification of $\beta$-globin genomic sequences and restriction site analysis for diagnosis of sickle cell anemia" Science 230, 1350-1354 (1985).

2. R.J.Lipshutz, D.Morris, M.Chee, E.Hubbell, M.J.Kozal, N.Shah, N.Shen, R.Yang, and S.P.A.Fodor, "Using Oligonucleotide Probe Arrays to Assess Genetic Diversity", BioTechniques, 19, $442-447$ (1995).

3. Cambridge Healthtech Institute, "The Human Genome Project: Commercial Implications", San Francisco, CA, 3/4$6 / 96$ (1996).

4. M. A. Northrup, "DNA Amplification with a Microfabricated Reaction Chamber" Transducers '93, 924 926, (1993).

5. P. Wilding, M.A. Shoffner, and L.J. Kricka, "PCR in a Silicon Microstructure" Clin. Chem., 40, 1815-1818, (1994).

6. P.M. Holland, R.D. Abramson, R. Watson, and D.H. Gelfand, "Detection of Specific Polymerase Chain Reaction Product by Utilizing the 5' to 3' Exonuclease Activity of Thermus aquaticus DNA Polymerase", Proc. Natl. Acad. Sci., 88, 7276-7280 (1991).

7. L.G. Lee, C.R. Connell, and W. Bloch, "Allelic Discrimination by Nick-translational PCR with Fluorogenic Probes", Nuc. Acids Research, 93, 3761-3766 (1993).

8. S.C. Jacobson and J.M. Ramsey, "Integrated Microdevice for DNA Restriction Fragment Analysis”, Anal. Chem., 68, $720-723$ (1996).

9. "Micro Total Analysis Systems", A.van den Berg and P. Bergveld (eds.), Kluwer Academic Publishers, The Netherlands (1995).

10. D.J. Harrison, K. Fluri, K. Seiler, Z. Fan, C. effenhauser and A. Manz, "Micromachining a Miniaturized Capillary Electrophoresis-Based Chemical Analysis System on a Chip" Science, 261, 895-897, 1993.

\section{ACKNOWLEDGMENTS}

This research was supported by The Department of Commerce, NIST-ATP. The following sites contributed technical resources: EG\&G IC Sensors (silicon parts), MicroFab Technologies (ink-jet heads) and SAIC (surface analysis). 